\title{
Individual Differences as Predictors of Seven Dance Style Choices
}

\author{
Carmen Amador Barreiro1, Adrian Furnham ${ }^{2 *}$ \\ ${ }^{1}$ Research Department of Clinical, Educational and Health Psychology, University College London, London, UK \\ ${ }^{2}$ Norwegian Business School (BI), Nydalveien, Olso, Norway \\ Email: *a.furnham@ucl.ac.uk
}

How to cite this paper: Barreiro, C. A., \& Furnham, A. (2019). Individual Differences as Predictors of Seven Dance Style Choices. Psychology, 10, 916-930.

https://doi.org/10.4236/psych.2019.106059

Received: April 15, 2019

Accepted: May 26, 2019

Published: May 29, 2019

Copyright (c) 2019 by author(s) and Scientific Research Publishing Inc. This work is licensed under the Creative Commons Attribution International License (CC BY 4.0).

http://creativecommons.org/licenses/by/4.0/

\begin{abstract}
The present study investigated recreational dancers of seven dance styles (Ballet, Contemporary, Jazz/Tap, Hip-Hop, Belly, Ballroom, Latin), their personal demographics, dance motivation and the Big Five personality traits. Three hundred and four participants indicated their dance style and answered motivation questions for each one. Further, they completed a measure of the Big Five personality traits. Factor analysis demonstrated three underlying motivation factors (Mood Enhancement, Fitness, and Self-Confidence) for each dance style. Mood Enhancement was the strongest predictor to dance in six out of seven dance styles. Limitations are acknowledged.
\end{abstract}

\section{Keywords}

Dance, Individual Differences, Personality, Motivation

\section{Introduction}

Dance is a celebrated human behaviour found in every culture, accompanying ancient rituals, gatherings and social events (McCarty et al., 2017). It is a form of exercise closely related to music, creativity, and often the presence and physical closeness of a partner (Maraz et al., 2015).

The motive to, and factors associated with choice and experience of dance have received increased attention in the literature (McCarty et al., 2017; Fink \& Shackelford, 2016). Some researchers have investigated how individual difference traits, such as personality, are related to dance choice and preferences. Further, there is a growing body of research, focusing on the motivation behind why dancers dance, including psychological, physiological, and mating reasons. The current study aims to uncover the underlying motivational factors of danc- 
ers of seven styles. Specifically, it is investigated how these motivations, along with individual differences, such as demographics and personality traits, predict choosing a particular dance style.

\subsection{Personality and Dance}

The body of personality work suggests that the Big Five personality traits are associated with a variety of creativity-related phenomena, including music preference (Chamorro-Premuzic et al., 2010), perception and experience of emotion in music (Vuoskoski \& Eerola, 2010) and art preference (e.g. Furnham \& Chamorro-Premuzic, 2004). Relationships between these five personality factors and recreational choice have also been documented (Kirkaldy \& Furnham, 1991).

Dance is a recreational and professional form of sport, which is closely related to music and creativity (Maraz et al., 2015). Dancers have been characterized as being more creative, introverted, scoring high on neuroticism and openness to experience (Alter, 1984; Bakker, 1991; Haller, 2010; Marchant-Haycox \& Wilson, 1992; Rubinstein \& Strul, 2006) compared to non-artists and non-dancers. Nevertheless, such studies tend to investigate a limited amount of dance styles and have focused mostly on female professionals.

Fink and Woschnjak (2011) investigated personality correlates of professional dancers of three different dance styles (Ballet, Modern/Contemporary and Jazz/Musical). Dancers of Modern/Contemporary (a style motivated by reducing the rigid structure of classical Ballet and involving free improvisation) showed high levels of Openness and low levels of Conscientiousness. Dancers of classical Ballet and Jazz/Musical exhibited higher levels of Conscientiousness and lower levels of Openness compared to Modern/Contemporary dancers. The results were attributed to the fact that Ballet and Jazz require more performance from pre-established choreographies and less creative input. These findings have been supported in the music domain. For example, individuals high in Openness, a trait that assesses intellectual curiosity, preferences for novel experiences and creativity, preferred complex compared to happy or sad music (Chamorro-Premuzic, Fagan, \& Furnham, 2009).

The personality trait Conscientiousness involves self-discipline, organisation and diligence and high scores on this trait overlap with descriptions of perfectionism (Nordin-Bates et al., 2012; Stoeber, Otto, \& Dalbert, 2009). Research has found, albeit in classical domains such as orchestral music and ballet, that it is common for performers to be classified as perfectionists in order to achieve high standards of excellence (Dews \& Williams, 1989; Van Staden et al., 2009). Nordin-Bates et al. (2011) recently found that high-level Ballet and Contemporary dance students had high and moderate perfectionist tendencies, and few students had no perfectionist tendencies.

It has been argued that personality traits such as Introversion and perfectionism may contribute to dancers' low self-esteem and anxiety. Performing artists such 
as dancers have been shown to suffer from low levels of self-esteem, self-confidence, or both (Bakker, 1991; Buckroyd, 2000; Neumärker, Bettle, Neumärker, \& Bettle, 2000; Laws, 2005; Marchant-Haycox \& Wilson, 1992). Factors such as feelings of exposure and vulnerability, having one's identity tightly bound to the performance activity and lack of feedback may cause these feelings (Fortin, 2009; Hays \& Brown Jr., 2004).

Bakker (1988) further suggested that the atmosphere of professional schools, which routinely criticise body appearance and physical abilities, might explain Ballet dancers' low self-esteem. The role of self-esteem in dance remains unclear, however, these findings are based on work with Ballet dancers (Neumärker et al., 2000) via a small qualitative study (Hanrahan, 1996), single-item self-report (Laws, 2005) or anecdotally (Buckroyd, 2000) and contrast findings stating that physical activity is positively correlated with self-esteem (Opdenacker, Delecluse, \& Boen, 2009).

\subsection{Dance Motivation}

Dance is frequently expressed in mating contexts and seems, in part, to function as a human courtship display serving to attract potential partners (Hanna, 2010; Hendrie et al., 2009; Hugill et al., 2011). Studies in this domain, however, have focused mainly on perceptions of others' dancing rather than considering why people dance. It has been found that women derive quality cues (physical strength, personality) from men's dance movements and vice versa (fertility cues) (see McCarty et al., 2017 for a review).

Few empirical studies have explored the motivations behind why people choose to dance, but a consensus in performance psychology seems to be that the pursuit of enjoyment is often the primary reason for engaging in a performing art (Bond \& Stinson, 2007; Houston, 2004; Papageorgi et al., 2010). Most studies exploring this domain, however, have used a descriptive-qualitative method of assessment (Nieminen, 1998; Nieminen, Varstala, \& Manninen, 2001). In an attempt to find underlying motivational factors of experienced dancers, Nieminen (1998) extracted four factors (namely, Self-expression, Social contact, Fitness, and Achievement/Performing) for Folk, Ballet, Ballroom-competitive, and Modern dance. Despite the study's heterogeneous sample, the questionnaire is not generalizable because certain items are not applicable to recreational dancers (e.g., are you "preparing for a career?") and substantial cross-loadings in principal component analysis limit the usability of the separate scales.

Maraz et al. (2015) developed the Dance Motivation Inventory (DMI), arguing that motivation is different in recreational compared to professional dancers as there is much evidence that recreational and professional athletes have distinct motivations. They found eight motivational factors: Fitness, Mood Enhancement, Intimacy, Socialising, Trance, Mastery, Self-confidence and Escapism. Mood Enhancement was the strongest motivational factor for both 
males and females, congruent to findings in the literature stating that the pursuit of enjoyment is often the primary reason for engaging in a performing art (Bond \& Stinson, 2007; Houston, 2004; Papageorgi et al., 2010; Stinson, 1997). Further supporting this finding, Domene and colleagues (2014) found that novice to advanced Latin dancers take part in classes particularly for leisure purposes and social enjoyment. Kreutz (2008) also found that tango dancing was considered a primary leisure activity, involving the opportunity for physical exercise, social interaction and emotional reward. In the current study, we adapted Maraz and colleagues' (2015) DMI to determine if similar factors would arise when investigating seven different dance styles.

\subsection{The Present Study}

The current study asked participants their motivations behind a range of dance styles including Ballet, Contemporary, Jazz/Tap, Hip Hop, Belly, Ballroom and Latin, asked less investigated demographic questions such as sexuality, and self-attractiveness ratings and also provided a personality test.

H1: There is an underlying structure regarding the motivations to dance certain styles.

$\mathrm{H} 2$ : Individual differences in demographics, personality traits and dance motivations are correlated to dance style choices.

H3: Individual differences in demographics, personality traits and dance motivations predict dance style choices.

$\mathrm{H}_{1}$ : High Conscientiousness increases the likelihood of choosing Ballet, Contemporary and Jazz.

$\mathrm{H}_{2}$ : High Openness to experience increases the likelihood of choosing Modern/Contemporary.

\section{Method}

\subsection{Participants}

304 participants were recruited over the Internet using emailing and social networking sites. This was done by the first author, a dancer, with her extensive network. There was a mixture of recreational dancers and non-dancers. The participants consisted of 232 females and 72 males, their ages ranging from 18 - 70 years $(M=27.41, S D=11.32)$. Two hundred and ninety-one participants identified themselves as heterosexual, and 13 as homosexual. They were all Europeans with the vast majority being British. Nearly all had completed their A levels $\left(12^{\text {th }}\right.$ grade).

\subsection{Measures}

\subsubsection{Dance Styles}

The dance styles include Ballet, Contemporary, Hip Hop, Jazz/Tap, Belly, Ballroom, and Latin. Under some dance styles, examples were given to facilitate the answers of the participants (e.g., Hip Hop: Break, Afrobeat, Waacking, Vogue; 
Ballroom: Waltz, Foxtrot, American Smooth; Latin: Salsa, Bachata, Samba, Cha Cha Cha, Merengue, Reggaeton, Lambada). Measures were taken of whether they danced the style or not, and how much they liked the dance style with a rating of $0-10$.

\subsubsection{Dance Motivation Scale}

The participants answered the same set of 15 questions for each of the seven dance styles. To measure motivation ratings for each dance, we constructed the Dance Motivation Scale, based on Maraz et al.'s (2015) Dance Motivation Inventory. Participants rated their opinion of what a dancer of the given style would answer from 0 (disagree completely) - 10 (agree completely).

\subsubsection{TIPI Personality Test (Gosling et al., 2003)}

After answering the Dance Motivation Scale for each of the seven dance styles, the personality test was administered to determine participants' Big Five personality traits: Extraversion, Emotional Stability, Agreeableness, Conscientiousness and Openness to Experiences.

\subsubsection{Demographics}

Finally, the participants were asked their sexual orientation, BMI, relationship status and ratings of self-attractiveness (i.e. rating from 0 - 10).

\section{Results}

\subsection{Frequencies}

The frequency and proportion of dancers per dance style was calculated and is shown in Table 1. Almost half of the sample (46.7\%) danced Contemporary, whereas the least danced style was Belly (14.5\%).

\subsection{Factor Analyses}

Participants' scores from the Dance Motivation Scale for all the dance styles underwent a factor analysis with a VARIMAX rotation. In this first analysis, 13 out of the 15 items correlated at least .45 with at least one other item, suggesting factorability Competitive and Vigorous motivations did not fit into any identified components due to less than. 45 correlations with the other items. This first analysis also showed that the Kaiser-Meyer-Olkin measure of sampling adequacy was .84, above the commonly recommended value of .6, and Bartlett's test of Sphericity was significant $\left(\chi^{2}(105)=4642.00, p<.001\right)$. Given these indicators, a second factor analysis was deemed to be suitable with 13 items. A second factor analysis with VARIMAX rotation reduced the remaining 13 items to three

Table 1. The frequency and proportion of responding "yes" to dancing a given style.

\begin{tabular}{cccccccc}
\hline & Ballet & Contemporary & Jazz/Tap & Hip Hop & Belly & Ballroom & Latin \\
\hline$N$ & 100 & 142 & 105 & 87 & 44 & 59 & 109 \\
$\%$ & 32.9 & 46.7 & 34.5 & 28.6 & 14.5 & 19.4 & 35.9 \\
\hline
\end{tabular}


components. The Factor Loading matrix for the VARIMAX rotation is presented in Table 2, which displays the results of the factor analysis including the mean, standard deviation and factor loading of each item.

The three rotated components explained $67.91 \%$ of the variance in total. The first component, labelled Fitness, was identified by 6 factors: Delicate, Fitness, Body Achievement, Flexibility, Balance and Mastery, and these explained 33.17\% of the variance. A new variable for this component was computed per dance style by averaging the scores for these 6 variables per participant per dance. Four items identified the second component, labelled Mood Enhancement: Enlivened, Fun, Self-esteem and Happy, and these explained $23.71 \%$ of the variance. These 4 items were averaged into a new variable per participant for each dance style. Four items also identified the third component, labelled Self-Confidence: Self-esteem, Attractive, Sassy, and Promiscuous, and these explained $11.04 \%$ of the variance. These 4 items were averaged into a new variable per participant for each dance style. The components were given the same names as Maraz et al. (2015) due to their similarity.

The internal reliability of the Motivations were Mood Enhancement .90, Fitness .91 and Self-Confidence .90 .

\subsection{Correlational Analysis}

Table 3 shows the results of the Pearson product-moment correlations between Demographic measures, Personality measures and the dance styles.

As shown in Table 3, Ballet correlates positively with Contemporary, Jazz and Ballroom, Contemporary and Jazz correlate positively with Hip Hop. Ballroom

Table 2. Factor loadings and principal components analysis with VARIMAX rotation for 13 items from the Dance Motivation Scale $(\mathrm{N}=304)$.

\begin{tabular}{|c|c|c|c|c|}
\hline A dancer of this style dances this to... & Fitness & $\begin{array}{c}\text { Mood } \\
\text { Enhancement }\end{array}$ & Self-Confidence & Communalities \\
\hline ...Feel enlivened & & .78 & & .65 \\
\hline ... Have fun & & .88 & & .82 \\
\hline$\ldots$ Increase self-esteem & .31 & .52 & .42 & .54 \\
\hline ... Feel happy & & .81 & & .68 \\
\hline ... Feel attractive & & & .77 & .68 \\
\hline ... Feel sassy & & .34 & .74 & .68 \\
\hline ... Feel promiscuous & & & .83 & .69 \\
\hline ... Feel delicate & .58 & -.38 & .32 & .58 \\
\hline$\ldots$ Improve fitness & .75 & & & .64 \\
\hline ... Strive for body ach & .83 & & & .74 \\
\hline ... Improve flexibility & .87 & & & .76 \\
\hline ... Improve balance & .88 & & & .78 \\
\hline ... Feel mastery over one's own body & .76 & & & .60 \\
\hline
\end{tabular}


Table 3. Descriptive statistics and inter-correlations between dance styles, demographic and personality measures.

\begin{tabular}{|c|c|c|c|c|c|c|c|c|c|c|c|c|c|c|c|c|c|c|c|c|}
\hline & $M(S D)$ & 2 & 3 & 4 & 5 & 6 & 7 & 8 & 9 & 10 & 11 & 12 & 13 & 14 & 15 & 16 & 17 & 18 & 19 & 20 \\
\hline 1. Ballet & $.33(.47)$ & $.51^{\star *}$ & $.51^{* *}$ & .08 & -.09 & $.12^{*}$ & .03 & $-.18^{* *}$ & $.31^{* *}$ & $-.12^{*}$ & -.01 & -.12 & .06 & -.09 & -.04 & .06 & .01 & $.18^{* *}$ & -.03 & .10 \\
\hline 2. Contemporary & .47(.50) & & $.51^{* *}$ & $.22^{* *}$ & -.10 & .09 & .00 & $-.13^{*}$ & $.26^{* *}$ & -.06 & -.04 & -.08 & .01 & -.02 & -.05 & .09 & .03 & $.14^{*}$ & -.02 & .06 \\
\hline 3. Jazz & $.35(.48)$ & & & $.23^{* *}$ & -.06 & $.13^{*}$ & -.07 & $-.17^{* *}$ & $.24^{* *}$ & -.05 & .05 & -.04 & .03 & -.05 & -.11 & -.03 & .01 & $.19^{* *}$ & -.10 & .01 \\
\hline 4. Hip hop & $.29(.45)$ & & & & -.03 & .04 & .03 & $-.14^{*}$ & .06 & -.08 & .05 & $-.12^{\star}$ & -.01 & -.09 & -.05 & -.06 & -.01 & .03 & -.08 & .04 \\
\hline 5. Belly & $.14(.35)$ & & & & & .01 & .10 & .10 & $.19^{* *}$ & .07 & -.09 & .02 & -.04 & .08 & .05 & -.03 & .05 & -.08 & $-.12^{*}$ & .02 \\
\hline 6. Ballroom & $.19(.40)$ & & & & & & $.34^{* *}$ & $.26^{* *}$ & .06 & $-.12^{*}$ & -.06 & $.11^{*}$ & -.08 & $.22^{\star *}$ & -.05 & .04 & .04 & $.12^{*}$ & -.03 & .08 \\
\hline 7. Latin & $.36(.48)$ & & & & & & & $.26^{* *}$ & .09 & -.04 & -.09 & .09 & -.08 & $.17^{* *}$ & .04 & $.12^{*}$ & .09 & -.05 & .088 & $.12^{*}$ \\
\hline 8. Age & $27.35(11.42)$ & & & & & & & .07 & $.12^{*}$ & -.43 & $.26^{* *}$ & $-.24^{\star *}$ & $.65^{* *}$ & -.06 & .08 & $.13^{*}$ & .01 & $.20^{* *}$ & .06 & -.08 \\
\hline 9. Gender & $1.76(.43)$ & & & & & & & & & -.04 & $-.23^{* *}$ & $-.14^{*}$ & -.03 & .07 & -.03 & .05 & .08 & $.12^{*}$ & $-.15^{*}$ & .05 \\
\hline 10. Instrument & $1.58(.50)$ & & & & & & & & & & .05 & $.14^{*}$ & -.10 & .08 & -.05 & .03 & .02 & -.02 & -.04 & $-.13^{*}$ \\
\hline 11. Sexuality & $1.04(.20)$ & & & & & & & & & & & -.06 & -.02 & -.08 & .01 & $.16^{* *}$ & -.02 & -.06 & -.01 & .1 \\
\hline 12. BMI & $22.57(3.64)$ & & & & & & & & & & & & .01 & $.11-$ & $-.24^{* *}$ & .02 & .05 & -.03 & -.01 & .06 \\
\hline 13. Religion & $3.20(1.96)$ & & & & & & & & & & & & & $-.21^{* *}$ & .01 & -.02 & -.04 & .04 & -.07 & .10 \\
\hline 14. Relationship & $1.75(.82)$ & & & & & & & & & & & & & & -.00 & $.14^{*}$ & .08 & .06 & .10 & .04 \\
\hline 15. Attractiveness & $6.35(1.51)$ & & & & & & & & & & & & & & & $.19^{* *}$ & .04 & $.14^{*}$ & $.22^{* *}$ & $.18^{* *}$ \\
\hline 16. Extraversion & $4.80(1.47)$ & & & & & & & & & & & & & & & & .03 & .10 & $.16^{* *}$ & $.32^{\star *}$ \\
\hline 17. Agreeableness & $4.83(1.09)$ & & & & & & & & & & & & & & & & & -.03 & $.26^{* *}$ & .11 \\
\hline $\begin{array}{l}18 . \\
\text { Conscientiousness }\end{array}$ & s $5.22(1.33)$ & & & & & & & & & & & & & & & & & & $.19^{* *}$ & .02 \\
\hline $\begin{array}{l}\text { 19. Emotional } \\
\text { Stab. }\end{array}$ & $4.62(1.41)$ & & & & & & & & & & & & & & & & & & & $.16^{* *}$ \\
\hline 20. Openness & $5.64(.10)$ & & & & & & & & & & & & & & & & & & & \\
\hline
\end{tabular}

further correlates positively with Jazz and Latin. Dance styles also significantly correlate with demographic measures. Ballet, Contemporary, Jazz/Tap and Hip Hop correlate negatively with age, and Ballroom and Latin correlate positively with age. All dance styles except for Hip Hop, Ballroom and Latin correlate positively with gender (specific genders will be referred to later in the regression analysis). BMI scores correlated negatively with Hip Hop and positively with Ballroom. Relationship status correlated positively with Ballroom and Latin. Extraversion correlated positively with Latin. Conscientiousness correlated positively with all dance styles except Hip Hop, Belly and Latin. Emotional stability correlated negatively with Belly. Openness correlated positively with Latin. The remaining variables did not correlate significantly with each other.

\subsection{Logistical Regression}

The data was then further analysed using binary logistical regression in order to find whether demographic, personality and motivational measures were significant predictors of choosing to dance each dance style. 
Ballet: The significant model $\left(\mathrm{X}^{2}(23)=99.55, p<.001\right.$ explained a moderate amount (39.4\%) of the variance in choosing to dance this style. Being female (B = 2.48), Odds 11.88) and having high conscientiousness $(B=0.26$, Odds 1.3) scores significantly increased the likelihood of choosing to dance Ballet. High Mood Enhancement motivations ( $\mathrm{B}=.29$, Odds 1.33 ) significantly increased the likelihood to dance Ballet, whereas high Self-Confidence scores $(B=-.23$, Odds .79) significantly decreased the likelihood to dance Ballet.

Contemporary. The significant $\left(\mathrm{X}^{2}(23)=63.53, p<001\right)$ model explained little amount $(25.7 \%)$ of the variance in choosing to dance this style. Being female $(\mathrm{B}=1.37$, Odds 3.94) and having high Mood Enhancement scores $(\mathrm{B}=.45$, Odds 1.56) significantly increased the likelihood of choosing to dance Contemporary.

Jazz: The significant model $\left(\mathrm{X}^{2}(23)=105.64, p<001\right)$ explained a moderate amount $(41.1 \%)$ of the variance in choosing to dance this style. Being female (B $=1.53$, Odds 4.60) heterosexual $(\mathrm{B}=2.01$, Odds 7.49), having high Mood Enhancement $(\mathrm{B}=.33$, Odds $=1.4)$ and Self-confidence $(\mathrm{B}=.32$, Odds 1.37$)$ scores significantly increased the likelihood of choosing to dance Contemporary. Older age ( $\mathrm{B}=-.05$, Odds .95), high self-attractiveness scores $(\mathrm{B}=-.28$, Odds .76$)$ and high extraversion scores $(\mathrm{B}=-.23$, Odds .80$)$ significantly decreased this likelihood.

Hip Hop: The significant model $\left(\mathrm{X}^{2}(23)=41.51, p<.001\right)$ explained little amount $(18.7 \%)$ of the variance in choosing to dance this style. Mood Enhancement $(\mathrm{B}=.39$, Odds 1.47$)$ was the only significant predictor, showing that high Mood Enhancement scores increased the likelihood to choose to dance Hip Hop.

Belly: The significant model $\left(\mathrm{X}^{2}(23)=87.31, p<.001\right)$ explained a moderate amount of variance $(45.2 \%)$ in choosing to dance this style. Despite the moderate amount, the model explains the most out of all the dance styles. High Fitness $(\mathrm{B}=.65$, Odds 1.92) and Mood Enhancement motivation $(\mathrm{B}=.57$, Odds $=$ 1.76) scores significantly increased the likelihood to choose to dance Belly, whereas high Emotional Stability ( $\mathrm{B}=-.33$, Odds $=.72)$ scores and high Self-confidence (B $=-.45$, Odds $=.64)$ scores significantly decreased the likelihood to dance this style.

Ballroom: The significant model $\left(\mathrm{X}^{2}(23)=58.69, p<.001\right)$ explained little amount of the variance (28.5\%) for choosing to dance Ballroom. Instrument (B $=-.10$, Odds $=.35$ ) was the only significant predictor, showing that playing an instrument significantly decreased the likelihood to dance Ballroom.

Latin: The significant model $\left(\mathrm{X}^{2}(23)=59.01, p<.001\right)$ explained a moderate amount $(24.7 \%)$ of the variance in choosing to dance this style. Older age (B $=.05$, Odds 1.06), and high Mood Enhancement motivation $(\mathrm{B}=.62$, Odds 1.86) scores significantly increased the likelihood of choosing to dance this style, whereas high Conscientiousness scores $(\mathrm{B}=-.23$, Odds .79) significantly decreased this likelihood. No other variables were found to be significant predictors.

In summary, three motivation factors (Mood Enhancement, Fitness and Self-Confidence) were found. There were several significant inter-correlations between the dance styles, demographic, personality and motivation measures 
and some of these variables were found to predict dance style choices.

\section{Discussion}

In line with the studies general aim, the current study found individual differences in demographics, Big Five personality traits and motivations relating to and predicting a range of seven dance style choices. Confirming our first hypothesis, an underlying dance motivation structure was found. The Dance Motivation Scale was found to consist of 3 components as opposed to eight as stated by Maraz et al. (2015). Nevertheless, given the similarity of Maraz and colleagues' motivation items and components, the same names were given: Mood Enhancement, Fitness and Self-Confidence.

Confirming the second and third hypotheses, four out of five personality traits correlated with dance styles and three personality traits predicted dancing certain styles. Supporting Hypothesis $3_{1}$, Conscientiousness correlated positively with all dances except for Hip Hop, Belly and Latin, and high scores on this trait increased the likelihood of dancing Ballet and decreased the likelihood of dancing Latin. This finding partly confirms Fink and Woschnjak (2011), who demonstrated that Ballet and Jazz/Tap dancers had higher conscientiousness scores than Contemporary dancers.

A possible explanation for conscientiousness predicting to dance Ballet is that the style is associated with following strict rules and choreography. This attracts high Conscientiousness scorers as they often display self-discipline, strive for achievement, and prefer planned rather than spontaneous behaviour. Contrastingly, Latin dancing encompasses highly improvised steps, synchronising with one's partner as well as taking the lead or being lead. Since partner dancing generally involves one male and one female, gender differences in Conscientiousness scores related to dancing should be explored in future research.

Furthermore, the personality trait Extraversion correlated positively with Latin dance, and high scores increased the likelihood (almost significantly) of dancing Latin and Jazz/Tap. Extraverts feel comfortable around people, are very sociable and like to be constantly stimulated (Costa Jr. \& McCrae, 1992). In line with music research however, it could be that the nature of Latin dance music attracts extraverts, as it has been found that extraverts prefer listening to happy music over sad or complex music (Chamorro-Premuzic et al., 2009) that might be associated more with Ballet and Contemporary styles. It should also be noted that the opposite trait, Introversion, did not predict dancing any of the styles as opposed to Bakker's $(1988,1991)$ research. Perhaps Introversion is more defining of professional Ballet students rather than of the current sample, which included a range of recreational dancers.

Despite the trait Openness to Experience correlating positively with Latin, Hypothesis $3_{2}$ was not supported by the current findings, as the trait did not predict to dance any styles. Perhaps this trait is more predictive of professional dancers as Fink and Woschnjak (2011) found that Contemporary dancers scored 
higher on Openness than Ballet and Jazz dancers. Fink and Woschnjak (2011) attributed dancers scoring high on Openness as also scoring high on creativity measures. Therefore, perhaps future research could compare dancers and choreographers (i.e. who are presumably more creative as they create dances) to gain more knowledge on how Openness to Experience relates to dance.

Agreeableness, however, did not relate to any dance styles in the current study or, in fact, in any dance or movement studies. The trait could simply not be associated with dance. Personality traits also failed to predict dancing Contemporary, Hip Hop and Ballroom. This result may be due to methodological shortcomings of the study. These dance styles encompass a wide array of sub-styles as, for example, Ballroom dancing can range from Foxtrot to Waltz. Future studies could use dance videos or specific descriptions of each dance style rather than just generic names that rely on the participants' knowledge to find personality predictors of such styles.

Overall, certain personalities have been found to predict dancing a number of dance styles. This is in line with the Self-Selection Hypothesis (Carr \& Wyon, 2003; Kogan, 2002; Marchant-Haycox \& Wilson, 1992; Wills \& Cooper, 1988). This hypothesis observes that individuals gravitate toward certain dance careers because of their personality, survive within this profession because of their personality and have this personality shaped due to their experience within that profession. Although the current study investigated recreational dancers, it could be that certain individuals gravitate more to one style over another because of their personality. Similarly, it would be interesting to see if any personality traits are identifiable in becoming a successful dancer (see Walker, Nordin-Bates, \& Redding, 2010 for a review on talent identification and development in dance).

Five out of eight demographic measures correlated significantly with dance styles, and a number of these significantly predicted dancing certain styles. For older age, it predicted a decreased likelihood of dancing Contemporary and Jazz, whereas it increased the likelihood to dance Latin. Contemporary and Jazz require higher levels of technique and stamina, perhaps explaining why older individuals are less likely to choose these styles. Moreover, Latin dance classes as well as Latin dance inspired fitness classes such as Zumba offered to adults are very common (NHS, 2017) and this could explain why older individuals (note that the mean age was 27.41 years and the age range was 18 - 70) engage in such dances. Perhaps Latin dancing also attracts older individuals because it is a partner dance and thus they can partake in a recreational activity with their partner. This suggestion is supported by the significant and positive correlation found between relationship status and Ballroom and Latin dancing.

Three motivations were found to underlie seven different dance style choices, namely: Mood Enhancement, Fitness and Self-Confidence. Mood Enhancement motivations for each style correlated positively with all the dance styles as well as significantly increased the likelihood to dance all the styles except for Ballroom. This finding therefore confirms the research in performance psychology sug- 
gesting that the pursuit of enjoyment is often the primary reason for engaging in a performing art (e.g., Bond \& Stinson, 2007; Houston, 2004; Papageorgi et al., 2010; Stinson, 1997). These findings are consistent with Maraz et al. (2015) findings that Mood Enhancement was a strong motivational factor for recreational dancers as well as Domene et al.'s (2014) findings that novice and advanced Latin dancers take part for leisure and social enjoyment.

The music in dance also facilitates group coordination and cohesion, social exchange, and regulation of movements, and internal and external imitation of music is a form of empathy, which can strengthen social bonds and release endorphins (Fink \& Shackelford, 2016; Leman, 2008; McNeill, 1995; Tarr, Launay, \& Dunbar, 2016). Thus, synchrony-based activities involving music such as dance may have developed due to the fact that they allow the release of endorphins in human communities, providing an alternative to social bonding mechanisms such as grooming. Quiroga Murcia et al. (2010) similarly found that dancing facilitates sympathy and elicits strong feelings of togetherness and affiliation.

In terms of Fitness motivations, it was found that they correlated with all dance styles except for Hip Hop, Ballroom and Latin but only predicted an increased likelihood in dancing Belly and a decreased likelihood in dancing Latin. It is possible that Belly dancers were motivated by Fitness reasons as the component encompassed items such as "feeling mastery over one's body" and "improving bodily achievement," and Belly dancing is an extremely difficult and technical style. Alternatively, it has been found that physical activity improves mental health and psychological wellbeing (Garber et al., 2011). Since Fitness and Mood Enhancement motivations correlated significantly and positively for each dance style, perhaps Belly dancers are motivated both by Fitness and Mood Enhancement motivations to dance and therefore receive the simultaneous positive effects.

Self-Confidence motivation was positively correlated with Jazz/Tap and Ballroom, and negatively correlated with Hip Hop. High Self-confidence scores decreased the likelihood to dance Ballet and Belly, but increased the likelihood to dance Jazz/Tap. These findings therefore indirectly suggest that Hip Hop, Ballet and Belly dancers suffer from low Self-confidence as opposed to dancers of other styles since the Self-Confidence questionnaire items included questions such as "I feel attractive" and they scored lowly. This supports the finding that performing artists, particularly Ballet dancers, have been shown to suffer from low levels of self-esteem and self-confidence (e.g., Bakker, 1988, 1991; Buckroyd, 2000; Hanrahan, 1996; Neumärker et al., 2000; Laws, 2005; Marchant-Haycox \& Wilson, 1992). Factors such as feelings of exposure and vulnerability and lack of feedback in these dance styles may cause these feelings (e.g., Fortin, 2009; Hays \& Brown Jr., 2004).

Lastly, it is worth noting that although the prediction models did explain more than half of the variance in choice in each dance style, correlations between dance styles and individual differences were relatively small. Therefore, it could be that other individual differences are also playing a role. Differences 
such as spatial ability (e.g., Tarampi, 2013), corporal self-perception and motor preferences (e.g., Cardoso et al., 2010) and beat perception (e.g., Ready et al., 2016) should be investigated in future dance research.

\section{Conclusion}

This paper explored individual differences in preference for dance styles, an area of research that has been relatively ignored. Gender, personality and particularly dance motivation were linked to an interest in, and preference for dance styles.

\section{Conflicts of Interest}

The authors declare no conflicts of interest regarding the publication of this paper.

\section{References}

Alter, J. B. (1984). Creativity Profile of University and Conservatory Dance Students. Journal of Personality Assessment, 48, 153-158. https://doi.org/10.1207/s15327752jpa4802_8

Bakker, F. C. (1988). Personality Differences between Young Dancers and Non-Dancers. Personality and Individual Differences, 9, 121-131. https://doi.org/10.1016/0191-8869(88)90037-2

Bakker, F. C. (1991). Development of Personality in Dancers: A Longitudinal Study. Personality and Individual Differences, 12, 671-681. https://doi.org/10.1016/0191-8869(91)90222-W

Bond, K. E., \& Stinson, S. W. (2007). “It's Work, Work, Work, Work”: Young People's Experiences of Effort and Engagement in Dance. Research in Dance Education, 8, 155-183. https://doi.org/10.1080/14647890701706115

Buckroyd, J. (2000). The Student Dancer. Emotional Aspects of the Teaching and Learning of Dance. Hightstown, NJ: Princeton Book Company Pub.

Cardoso, F. L., Silveira, R. A., Zequinão, M. A., Martins, C., \& Souza, C. A. (2010). Corporal Self-Perception and Motor Preferences of Dance Practitioners. Movimento: Revista da Escola de Educação Física, 16, 97-112.

Carr, S., \& Wyon, M. (2003). The Impact of Motivational Climate on Dance Students' Achievement Goals, Trait Anxiety and Perfectionism. Journal of Dance Medicine and Science, 7, 105-114.

Chamorro-Premuzic, T., Burke, C., Hsu, A., \& Swami, V. (2010). Personality Predictors of Artistic Preferences as a Function of the Emotional Valence and Perceived Complexity of Paintings. Psychology of Aesthetics, Creativity, and the Arts, 4, 196. https://doi.org/10.1037/a0019211

Chamorro-Premuzic, T., Fagan, P., \& Furnham, A. (2009). Personality and Uses of Music as Predictors of Preferences for Music Consensually Classified as Happy, Sad, Complex, and Social. Psychology of Aesthetics, Creativity, and the Arts, 4, 205. https://doi.org/10.1037/a0019210

Costa Jr., P. T., \& McCrae, R. R. (1992). Revised NEO Personality Inventory (NEO-PI-R) and NEO Five Factor Inventory (NEO-FFI): Professional Manual. Odessa, FL: Psychological Assessment Resources.

Dews, C. L. B., \& Williams, M. S. (1989). Student Musicians’ Personality Styles, Stresses, 
and Coping Patterns. Psychology of Music, 17, 37-47.

https://doi.org/10.1177/0305735689171004

Domene, P. A., Moir, H. J., Pummell, E., \& Easton, C. (2014). Physiological and Perceptual Responses to Latin Partnered Social Dance. Human Movement Science, 37, 32-41. https://doi.org/10.1016/j.humov.2014.06.009

Fink, A., \& Woschnjak, S. (2011). Creativity and Personality in Professional Dancers. Personality and Individual Differences, 51, 754-758. https://doi.org/10.1016/j.paid.2011.06.024

Fink, B., \& Shackelford, T. K. (2016). Why Did Dance Evolve? A Comment on Laland, Wilkins, and Clayton (2016). Evolutionary Psychological Science, 3, 147-148. https://doi.org/10.1007/s40806-016-0075-3

Fortin, S. (2009). The Dominant Artistic Discourse as a Health Determinant.

Furnham, A., \& Chamorro-Premuzic, T. (2004). Personality, Intelligence, and Art. Personality and Individual Differences, 36, 705-715. https://doi.org/10.1016/s0191-8869(03)00128-4

Garber, C. E., Blissmer, B., Deschenes, M. R., Franklin, B. A., Lamonte, M. J., Lee, I. M., Swain, D. P. et al. (2011). American College of Sports Medicine Position Stand. Quantity and Quality of Exercise for Developing and Maintaining Cardiorespiratory, Musculoskeletal, and Neuromotor Fitness in Apparently Healthy Adults: Guidance for Prescribing Exercise. Medicine and Science in Sports and Exercise, 43, 1334-1359. https://doi.org/10.1249/MSS.0b013e318213fefb

Gosling, S. D., Rentfrow, P. J., \& Swann, W. B. (2003). A Very Brief Measure of the Big-Five Personality Domains. Journal of Research in Personality, 37, 504-528. https://doi.org/10.1016/S0092-6566(03)00046-1

Haller, C. S. (2010). Personality and Thinking Style in Different Creative Domains. Psychology of Aesthetics, Creativity, and the Arts, 4, 149-160. https://doi.org/10.1037/a0017084

Hanna, J. L. (2010). Dance and Sexuality: Many Moves. Journal of Sex Research, 47, 212-241. https://doi.org/10.1080/00224491003599744

Hanrahan, S. J. (1996). Dancers' Perceptions of Psychological Skills. Revista de Psicologia del Deporte, 5, 19-27.

Hays, K. F., \& Brown Jr., C. H. (2004). You're on! Consulting for Peak Performance. Washington DC: American Psychological Association. https://doi.org/10.1037/10675-000

Hendrie, C. A., Mannion, H. D., \& Godfrey, G. K. (2009). Evidence to Suggest That Nightclubs Function as Human Sexual Display Grounds. Behaviour, 146, 1331-1348. https://doi.org/10.1163/156853909X427704

Houston, S. (2004). The Seriousness of Having Fun: The Political Agenda of Community Dance. Animated, Winter 2004.

http://www.communitydance.org.uk/metadot/index.pl?id=22439\&isa=DBRow\&op=sh ow\&dbview_id=17860

Hugill, N., Fink, B., Neave, N., Besson, A., \& Bunse, L. (2011). Women's Perception of Men's Sensation Seeking Propensity from Their Dance Movements. Personality and Individual Differences, 51, 483-487. https://doi.org/10.1016/j.paid.2011.05.002

Kirkcaldy, B., \& Furnham, A. (1991). Extraversion, Neuroticism, Psychoticism and Recreational Choice. Personality and Individual Differences, 12, 737-745. https://doi.org/10.1016/0191-8869(91)90229-5

Kogan, N. (2002). Careers in the Performing Arts: A Psychological Perspective. Creativity 
Research Journal, 14, 1-16. https://doi.org/10.1207/S15326934CRJ1401_1

Kreutz, G. (2008). Does Partnered Dance Promote Health? The Case of Tango Argentino. Journal of the Royal Society for the Promotion of Health, 128, 79-84. https://doi.org/10.1177/1466424007087805

Laws, H. (2005). Fit to Dance 2. Report of the Second National Inquiry into Dancers Health and Injury in the UK. London: Dance UK.

Leman, M. (2008). Embodied Music Cognition and Mediation Technology. Cambridge, MA: MIT Press. https://doi.org/10.7551/mitpress/7476.001.0001

Maraz, A., Király, O., Urbán, R., Griffiths, M. D., \& Demetrovics, Z. (2015). Why Do You Dance? Development of the Dance Motivation Inventory (DMI). PLoS ONE, 10, e0122866. https://doi.org/10.1371/journal.pone.0122866

Marchant-Haycox, S. E., \& Wilson, G. D. (1992). Personality and Stress in Performing Artists. Personality and Individual Differences, 13, 1061-1068. https://doi.org/10.1016/0191-8869(92)90021-G

McCarty, K., Darwin, H., Cornelissen, P. L., Saxton, T. K., Tovée, M. J., Caplan, N., \& Neave, N. (2017). Optimal Asymmetry and Other Motion Parameters That Characterise High-Quality Female Dance. Scientific Reports, 7, Article No. 42435. https://doi.org/10.1038/srep42435

McNeill, W. H. (1995). Keeping Together in Time: Dance and Drill in Human History. Cambridge, MA: Harvard University Press.

Neumärker, K. J., Bettle, N., Neumärker, U., \& Bettle, O. (2000). Age- and Gender-Related Psychological Characteristics of Adolescent Ballet Dancers. Psychopathology, 33, 137-142. https://doi.org/10.1159/000029135

NHS (2017). Dance for Fitness. http://www.nhs.uk/Livewell/getting-started-guides/Pages/getting-started-dancing.aspx

Nieminen, P. (1998). Participation Motives in Relation to Background and Involvement Variables among Finnish Non-Professional Dancers. Dance Research Journal, 30, 53-70. https://doi.org/10.2307/1478838

Nieminen, P., Varstala, V., \& Manninen, M. (2001). Goal Orientation and Perceived Purposes of Dance among Finnish Dance Students: A Pilot Study. Research in Dance Education, 2, 175-193. https://doi.org/10.1080/14647890120100791

Nordin-Bates, S. M., Cumming, J., Aways, D., \& Sharp, L. (2011). Imagining Yourself Dancing to Perfection? Correlates of Perfectionism in Ballet and Contemporary Dance. Journal of Clinical Sport Psychology, 5, 58-76. https://doi.org/10.1123/jcsp.5.1.58

Nordin-Bates, S. M., Quested, E., Walker, I. J., \& Redding, E. (2012). Climate Change in the Dance Studio: Findings from the UK Centres for Advanced Training. Sport, Exercise, and Performance Psychology, 1, 3-16. https://doi.org/10.1037/a0025316

Opdenacker, J., Delecluse, C., \& Boen, F. (2009). The Longitudinal Effects of a Lifestyle Physical Activity Intervention and a Structured Exercise Intervention on Physical Self-Perceptions and Self-Esteem in Older Adults. Journal of Sport and Exercise Psychology, 31, 743-760. https://doi.org/10.1123/jsep.31.6.743

Papageorgi, I., Haddon, E., Creech, A., Morton, F., De Bezenac, C., Himonides, E. et al. (2010). Institutional Culture and Learning I: Inter-Relationships between Perceptions of the Learning Environment and Undergraduate Musicians' Attitudes to Learning. Music Education Research, 12, 151-178. https://doi.org/10.1080/14613801003746550

Quiroga Murcia, C., Kreutz, G., Clift, S., \& Bongard, S. (2010). Shall We Dance? An Exploration of the Perceived Benefits of Dancing on Well-Being. Arts and Health, 2, 149-163. https://doi.org/10.1080/17533010903488582 
Ready, E. A., McGarry, L. M. J., Rinchon, C., Holmes, J. D., \& Grahn, J. A. (2016). Free-Walking and Synchronized Rhythmic Auditory Stimulation. Personality and Individual Differences, 101, 509. https://doi.org/10.1016/j.paid.2016.05.272

Rubinstein, G., \& Strul, S. (2006). The Five Factor Model (FFM) among Four Groups of Male and Female Professionals. Journal of Research in Personality, 41, 931-937. https://doi.org/10.1016/j.jrp.2006.09.003

Stinson, S. W. (1997). A Question of Fun: Adolescent Engagement in Dance Education. Dance Research Journal, 29, 49-69. https://doi.org/10.2307/1478734

Stoeber, J., Otto, K., \& Dalbert, C. (2009). Perfectionism and the Big Five: Conscientiousness Predicts Longitudinal Increases in Self-Oriented Perfectionism. Personality and Individual Differences, 47, 363-368. https://doi.org/10.1016/j.paid.2009.04.004

Tarampi, M. R. (2013). Use of Spatial Transformations and Reference Frames. Individual Differences in Spatial Ability. Utah: University of Utah.

Tarr, B., Launay, J., \& Dunbar, R. I. (2016). Silent Disco: Dancing in Synchrony Leads to Elevated Pain Thresholds and Social Closeness. Evolution and Human Behavior, 37, 343-349. https://doi.org/10.1016/j.evolhumbehav.2016.02.004

Van Staden, A., Myburgh, C. P. H., \& Poggenpoel, M. (2009). A Psycho-Educational Model to Enhance the Self-Development and Mental Health of Classical Dancers. Journal of Dance Medicine and Science, 13, 20-28.

Vuoskoski, J. K., \& Eerola, T. (2010). Domain-Specific or Not? The Applicability of Different Emotion Models in the Assessment of Music-Induced Emotions. In S. M. Demorest, S. J. Morrison, \& P. S. Campbell (Eds.), Proceedings of the 11th International Conference on Music Perception and Cognition (ICMPC11) (pp. 196-199).

Walker, I. J., Nordin-Bates, S. M., \& Redding, E. (2010). Talent Identification and Development in Dance: A Review of the Literature. Research in Dance Education, 11, 167-191. https://doi.org/10.1080/14647893.2010.527325

Wills, G., \& Cooper, C. L. (1988). Pressure Sensitive: Popular Musicians under Stress. London: Sage. 